\title{
CORRELATION BETWEEN THE INDIVIDUAL'S EXPERIENCE OF WELL-BEING AND SOCIAL EVALUATION
}

\author{
TETIANA DANYLCHENKO \\ Department of Psychology, Academy of the State Penitentiary Service \\ Honcha 34, 14000 Chernihiv, Ukraine \\ E-mail address: dan20151975@gmail.com \\ ORCID: https://orcid.org/0000-0001-8809-0132
}

\begin{abstract}
Aim. The aim of this paper is to define the correlation between social evaluation and personal well-being.

Methods. The study involved the citizens of Chernihiv (average age -31.5 years old): 91 people in total, 37 men and 54 women. The following methods were used: the scale of satisfaction with life scale by Diener, as adapted by Leontiev and Osin (2008); questionnaire of parameters of subjective social well-being by Danylchenko (2015); subjective life satisfaction scale by Lybyna (2008), questionnaire on the peculiarities of evaluation by other people by Danylchenko (2019).

Results and conclusion. In Ukrainian society, the most important reference groups are parents and a spouse, while friends and colleagues play a comparatively smaller role. All these groups are more likely to give positive and neutral social evaluations. However, negative evaluations are more likely to come from colleagues and friends, and positive - from family. There are differences in indicators of subjective well-being, social acceptance (as a measure of social well-being) and competence between people who are assessed predominantly positively and predominantly negatively. Subjective well-being is reduced reproaches from reference groups. Praise contributes to the enhancement of subjective social well-being Comparison with other people and the existence of a role model reduces psychological well-being. The filter for the perception of positive and negative evaluations from the social environment is a person's self-acceptance.

Cognitive value. The article shows the features of social evaluation that change the level of personal well-being.

Key words: psychological well-being, subjective well-being, subjective social well-being, social evaluation, approval, deprecation
\end{abstract}

\section{INTRODUCTION}

We evaluate ourselves and the social world a dozen times each day. Evaluations are an integral part of our lives and a regulator of our behaviour; they usually have both explicit and implicit effects on our consciousness. 
Despite being out of the zone of actual experiences, they have an extraordinary impact on an individual's mood and well-being. A study of the peculiarities of communication on social networks found that such type of communication can become a source of bad mood and irritation: $45 \%$ of respondents were jealous of friends whose posts provoked more reaction than theirs, while $45 \%$ were worried because no one "liked" their photo or there were less "likes" than they had expected (Zotova, 2017).

There are several fields in psychology that study evaluation. The first is represented by socio-psychological research and relates to studying the forms of evaluative reactions from others (forms of expressing approval and condemnation: reproaches, accusations, praise, compliments, etc.). The second is represented by the cognitive research of processing social judgments, in particular positive prejudices and the construction of reference images. Finally, the third is dedicated to the study of cognitive (protective mechanisms, lowered selfesteem), behavioural (conformal or conflict behaviour) and affective (envy, pride) reactions to evaluative judgments.

The process of forming judgment has certain errors. In particular, the phenomenon of positive prejudices is studied. This is the common human impulse to maximise the feeling of well-being for objective circumstances as much as possible (Samoilenko, 2010). One of the forms of judgment subjectivity is an individual's belief that he/she will not personally encounter negative situations. Accordingly, people underestimate the risks, in particular the need to adhere to safety rules (Kahneman \& Tversky, 1996). The effect of "above average" or illusory superiority is also well-known: positive personality traits (including the level of happiness) are overestimated, whereas the negative qualities are underestimated (Pronin, Lin, \& Ross, 2002). Furthermore, there is a phenomenon of distorting evaluations, which is connected with retrospective memory: people often devalue past achievements and express certain personality traits less to seem more capable to themselves and others in the present (Wilson \& Ross, 2001).

Another field of research comprises the study of evaluating others and the process of its expression. In particular, the Dunning-Kruger effect was identified: to assess someone's competence in a particular sphere, the evaluator needs to be competent in this area himself/herself (Dunning \& Kruger, 1999). This rule explains why an incompetent person is unable to understand their own incompetence. The two most studied forms of expressing the evaluation of others are devaluation and approval. It should be noted that, according to researchers (e.g. Rodriguez, 2013), the experience of well-being requires both positive and negative evaluations. Otherwise, a constant positive state becomes a priority, and, therefore, negatively affects interpersonal relationships and professional efficiency (Peralta \& Saldanha, 2017).

In the context of the impact on subjective social well-being, three areas of devaluation are distinguished: devaluation of oneself, others and a situation. In our study, we were interested in the devaluation of other people. Ken Mellor and Eric Schiff (1975) define depreciation as a phenomenon of depriving 
another person's actions and achievements of value and significance. Depreciation may lead to giving up an activity by reducing the significance of another person's actions or achievements, to continuing the established form of interaction with the person without changing own behaviour, and thus, to maintaining the previous level of own well-being.

Not only is approval itself studied as a means of social normalisation, but also its neuropsychological nature. In particular, it has been demonstrated that the neurophysiological response of the brain is the same to financial and social rewards, meaning that people can enjoy altruistic behaviour (Buchanan \& Bardi, 2010). The striatum (a part of the brain associated with social interaction and the ability to feel pleasure) has been identified to play a role in experiencing well-being (Izuma, Saito, \& Sadato, 2010). The quality of social approval is important for experiencing well-being, while social rejection expressed by anyone reduces well-being (Burnett, 2018).

A person is also the subject of his/her own evaluations and carries out purposeful activities in order to be evaluated in a certain way by public opinion. Nevertheless, Alexey Tikhomirov claims that external evaluations are always biased: they can be exaggerated by the inner circle (parents, spouses, friends) and underestimated by colleagues or strangers (Tikhomirov, 2016).

An indirect study of the impact of assessment on well-being is presented in studies on social comparisons. A frequent comparison process reduces the level of well-being (Daniychenko, 2014). Researchers have also noticed that social comparisons carry consequences, such as envy (Bers \& Rodin, 1984). A study by Peter Salovey and Judith Rodin indicates that a higher level of envy is recorded in those recipients who receive negative information regarding the success of tasks that are personally significant for them, while simultaneously learning about the successful completion of similar tasks by others (Salovey \& Rodin, 1984).

It is worth noting that people are sensitive to judgments that concern them to a different degree and react differently to the opinions that other people hold of them. Nevertheless, approval and condemnation are important regulators of social behaviour. Such judgments voiced in communication can significantly affect the experience of well-being, especially its social aspect. In our opinion, the study of the links between social evaluations and the dynamics of individual well-being has not been given due attention yet. That is why $t$

he aim of the study is to determine the impact of social evaluation on an individual's experience of well-being.

\section{METHODS}

The study involved adult citizens of Chernihiv, aged 21-58, with the average age being 31.5 years old. The participants had different professions. The total number of participants amounted to 91 people - 37 men and 54 women. The study was conducted using the following methodologies: the scale of 
satisfaction with life scale by Diener, as adapted by Leontiev and Osin (2008); questionnaire of parameters of subjective social well-being by Danylchenko (2015); subjective life satisfaction scale by Lybyna (2008), questionnaire on the peculiarities of evaluation by other people by Danylchenko (2019). The results were calculated using such mathematical and statistical methods as frequency, variance and regression analysis. The mathematical and statistical processing of the results was carried out using the software packages SPSS Statistica 22.0 and AMOS 18.

\section{ANALYSIS RESULTS}

The study found that the level of respondents' personal well-being is average, meaning that, according to Diner's method, the level of subjective wellbeing amounted to 21.49 points (implying that the respondents are satisfied with life to a small extent). In our opinion, such a level is typical for Ukrainian respondents as the results of our previous research conducted over the past five years have also fluctuated between 20.5 and 21.9 (Danylchenko, 2020).

The overall level of psychological well-being amounted to 217.9 points -7 stanines, and its components ranged from 6 stanines (self-acceptance, positive relationships, life goals) to 7 (autonomy, competence, personal growth). Therefore, the level of psychological well-being is quite high.

Finally, the subjective social well-being was also quite high -118.4 points (6 stanines). The lowest indicators were the scales of social distance (5 stanines) and emotional acceptance (5 stanines), whereas the highest - social visibility (7 stanines), social approval (7 stanines), and social judgments (7 stanines).

Typical reference groups for an individual are family, friends and (alternatively) colleagues and leisure groups. No statistically significant differences were found regarding the frequency of individual evaluations for men and women. The study revealed that a person evaluating respondents most often is their mother: $45.7 \%$ of men and $46.2 \%$ of women indicated their mother as a person who evaluates them more often than others. The next person offering most frequent evaluations is the spouse $(31.4 \%$ and $38.5 \%$, respectively), followed by friends $(25.7 \%$ and $28.8 \%)$. Peer colleague evaluations are also frequent: they were indicated by $28.6 \%$ of male respondents and $23.1 \%$ of female respondents. Men also indicated their father and siblings as reference persons $-17.1 \%$ for both; this score was lower for women, as only $9.6 \%$ and $7.7 \%$ of the respondents pointed to their father and siblings as reference persons respectively. Furthermore, men notice the evaluations by strangers $(14.3 \%)$ more often than women $(9.6 \%)$. Interestingly, women pay more attention to the evaluations by relatives ( $9.6 \%$ vs. $5.7 \%$ for men), while men to the evaluations by neighbours (5.7\% vs. 3.8\% for women). The obvious result of the survey is that family, along with friends and colleagues, remains the most relevant reference group. This regularity applies equally to men and women. 
There was no statistically significant difference between men and women as for the importance of evaluations offered by others. Thus, on a 10-point scale, the most important is the opinion of a spouse (7.9), mother (7.49), friends (6.79), father (6.4), siblings (6.12), colleagues (5.29), with the opinions of neighbours (3.09) and outsiders (2.66) being significantly lower. An interesting picture emerges when it comes to relationships with other relatives. A small number of respondents indicated them as persons whose evaluations are important: grandmother was offered by 10 respondents, uncle by 9 , grandfather by 5 . However, the level of significance of their evaluations for these respondents is remarkably high: 7.64, 6.11 and 9.4 points, respectively.

Methodological triangulation was used to determine the nature of the effect of external evaluations on the experience of personal well-being: the results obtained during an associative experiment and subjective scaling were compared. All characteristics of qualitative evaluations provided to respondents by their immediate environment were subjected to content analysis. The survey analysed three aspects of evaluation: appearance, behaviour, and personality of such subjects as parents, spouses, friends and colleagues.

At the first stage, the most frequently mentioned characteristics were identified. Thus, during the evaluation of the appearance, the most used categories were: "beautiful" (36 times from parents, 28 from a spouse, 24 from friends, 17 from colleagues), "pretty" (16 times from parents, 3 times from a partner, 8 times from friends, 5 times from colleagues), "cute" (7 times from parents, 4 times from a spouse, 7 times from friends, 5 times from colleagues). At the next stage, all categories were divided into three groups in accordance with their emotional colouring. In particular, evaluations of appearance such as "beautiful," "pretty," "attractive," or "good-looking" were classified as positive, whereas evaluations such as "fat," "unfashionable," or "horse" as negative. All other evaluations that did not have a clear evaluative connotation were classified as neutral.

In describing the behaviour, the most commonly used adjectives were "calm" (13 times from parents, 4 times from a partner, 7 times from friends, 5 from colleagues), "responsible" (6 times, 4 times, 8 times, 10 times respectively), "kind" (8, 12, 5, and 1 time respectively) and "quiet" (3, 2, 4, and 3 times respectively). Negative characteristics included "rude," "disobedient," "irresponsible," "unreserved," and "vindictive." It should be noted that most categories in the evaluation of behaviour are concerned with emotional selfregulation ("rude," "emotional," "arrogant," "crazy," "calm," "hysterical," or "energetic") and compliance with social rules ("well-behaved," "following the rules," "exemplary," "obedient," "reliable" etc.).

The greatest variability was observed in describing the respondents' personality since about 120 descriptors were indicated. Such variability is rooted in the implicit concept of personality. During life, each person builds his/her own hierarchy of significance/insignificance of certain personal manifestations depending on their own life experience. The following positive personality traits were most often mentioned: "kind" (11 times from parents, 8 from a spouse, 11 from 
friends, 7 from colleagues), "sociable" (2, 2, 9, and 5 times respectively), "smart" $(11,5,2$, and 3 times respectively), "purposeful" (5, 1, 1, and 2 respectively), "creative" (2, 4, 2, and 2 times respectively). The most frequently mentioned negative descriptors were: "quarrelsome," "non-punctual," and "rude."

In general, we can establish the clear dominance of positive and neutral evaluations in social communication. Negative evaluations were more often given by colleagues and friends, while spouses and parents were more cautious in giving negative statements addressed to the respondents.

During the third stage, based on the results of content analysis and subjective scaling of the types of social evaluations that were previously conducted with the respondents, all respondents were divided into three categories: 1 ) those who more often received positive evaluations in communication with others (42 persons); 2) those who more often received negative evaluations from others (8 people); 3 ) those who either received a balanced number of negative and positive evaluations, or received a large number of emotionally neutral evaluation judgments from others (41 people).

The results of the comparison between these three groups in terms of wellbeing are presented in the following table (Table 1):

Table 1

Indicators of individual well-being depending on the nature of the evaluations by others $(M)$

\begin{tabular}{lcccc}
\hline & $p$ & \multicolumn{3}{c}{ Predominant social evaluations } \\
& & 1 (positive) & 2 (negative) & 3 (neutral) \\
\hline $\begin{array}{l}\text { Subjective (hedonistic) well- } \\
\text { being }\end{array}$ & .01 & $23.50 \uparrow$ & $18.50 \downarrow$ & 20.02 \\
Psychological (eudaemonic) & - & 219.40 & 212.37 & 217.51 \\
well-being & - & 34.71 & 33.25 & 34.88 \\
Autonomy & -05 & $35.52 \uparrow$ & $30.37 \downarrow$ & $34.88 \uparrow$ \\
Competence & - & 37.64 & 41.37 & 38.90 \\
Personal growth & - & 38.19 & 37.12 & 36.66 \\
Positive relationships & - & 37.38 & 37.62 & 36.83 \\
Life goals & - & 35.95 & 32.63 & 35.37 \\
Self-acceptance & - & 125.0 & 110.12 & 113.24 \\
Subjective social well-being & - & 47.0 & 43.1 & 46.75 \\
Social visibility & - & 20.5 & 23.87 & 20.1 \\
Social distancing & - & 40.38 & 35.75 & 37.15 \\
Emotional acceptance & .05 & $37.52 \uparrow$ & $31.37 \downarrow$ & 35.37 \\
Social approval & .05 & $20.6 \uparrow$ & $20.13 \uparrow$ & $17.73 \downarrow$ \\
Positive social judgments & & & & \\
\hline
\end{tabular}

Note: ${ }^{*} \downarrow$ - groups that are different from the others at a statistically significant level Source: own research.

Therefore, we can see that a statistically significant difference in the groups was found only in terms of hedonistic well-being, which is more related to emotional reactions. The results obtained through the questionnaire of param- 
eters of subjective social well-being confirm that there is a preference for social approval displayed by those who perceive evaluative reactions from others as positive. The respondents given predominantly negative incentives evaluate lower their own competence - the ability to cope with everyday affairs and to create a context for the realisation of personal needs and values. Interestingly, there is a relatively low level of basic beliefs positivity (6 stanines) in respondents that receive ambivalent reactions from others. This indicator reflects a belief in people and favour of the world.

The survey revealed that there are different leading emotional states in each of the distinguished groups. Thus, the quantitative data confirms $(\mathrm{p} \leq .001)$ that people who receive more negative evaluations feel depressed and upset ( $\mathrm{M}=6.75$ on a 10-point scale), as well as experience apathy (6.63) and anxiety (7.02). On the contrary, respondents from the "positive" group are much less depressed (2.85), apathetic (3.22), or anxious (4.13). Different levels of satisfaction with relationships with acquaintances and relatives were also recorded (at the level of significance amounting to .05), which were higher among the respondents from the first group (on a 5-point scale: 3.95 and 3.90 respectively) and lower among the second (3.0 for both).

Causal relationship between emotions and the experience of well-being poses a separate scientific case because, in recent years, socio-psychological studies of this phenomenon have revealed reciprocal links. On the one hand, positive emotions can increase the ability to control emotions, as well as to form a state of well-being (Fredrickson, 2001). On the other hand, the theory of expansion and construction of positive emotions (the broaden-and-build theory) assumes that events evoking positive emotions, in their turn, lead to an instantaneous expansion of consciousness (attention, thinking) and inspire new cognitive actions. Hence, in a positive state, a person attaches greater importance to social incentives coming from specific persons and, to some extent, ignores negative statements. Therefore, there is a reciprocal relationship: emotions affect the experience of well-being, and the level of well-being determines the selective response to positive and negative stimuli.

In the proposed study, in order to determine the nature of the impact of social evaluations on well-being, regression analysis was used, in which the dependent variables were indicators of individual well-being, whereas the independent indicated the nature of evaluative reactions from others (without specifying the source of such evaluations).

The step-by-step regression analysis revealed that only one factor reduces subjective well-being, i.e. the frequency of reproaches addressed to the respondent which are expressed in sharp, offensive words (contribution to the total variance amounted to $12.9 \%, \beta=-0.359, \mathrm{p} \leq .01)$. The experience of subjective social well-being $\left(\mathrm{R}^{2}=.151\right)$ was influenced by the same factor, i.e. reproaches $(5.8 \%, \beta=-.415, p \leq .001)$, together with its antipode - the expression of a favourable reference about the respondent $(9.4 \%, \beta=0.353, p \leq .01)$. It was not condemnation or approval from others that were important for experiencing psychological well-being, but the individual style of respondent's self-comparison 
with other people. Thus, in the course of step-by-step regression analysis, the frequency of comparing own achievements with the achievements of significant people assumed the first place $(16.5 \%$ variance). Moreover, frequent comparisons reduced the experience of psychological well-being $(\beta=-.357, p \leq .001)$.

The second place $(5.4 \%)$ belongs to the factor of the frequency of others referring to role models whom the respondent should look up to. The higher the frequency of references, the lower the level of well-being was $(\beta=-.238, p \leq .01)$. It should be pointed out that $47.2 \%$ of men and $46.2 \%$ of women noted the existence of role models. Usually, role models are described as a phenomenon of children's socialisation. However, studies have confirmed that a similar phenomenon is to some extent characteristic of adults (Tesser \& Collins, 1988). The difference is that, for adults, it is usually not a specific person, but a generalised image that absorbs the traits of many people who are respected and admired. In our study, the most frequent figures for reference identification were parents (5 mentions), a father (4), a mother (3), a husband/wife (3), a teacher (3), friends (2), or a leader (2). It should be noted that the presence of such models can lead to frequent comparisons and, consequently, lower self-esteem. Avraam Tesser's theory of self-evaluation maintenance indicates that people who are more successful than others experience positive emotions and maintain high self-esteem, especially if they compare themselves with loved ones in an area important for self-determination. On the contrary, if loved ones are more successful, a person feels threatened for own well-being (Tesser, 1999). Therefore, according to Tesser, one of the mechanisms for maintaining positive self-esteem is distancing oneself from loved ones. The results of this study indicate this is especially true for men who, according to gender stereotypes, must comply with the norms of physical, intellectual and emotional rigidity. Conversely, the concepts that involve autonomy as a key element of personal maturity point out that the most important characteristic of optimal development is realising personal uniqueness (Deci \& Ryan, 2000). This means that the role of an authoritative role model is reduced to experience personal well-being.

Many concepts state that the key aspects of an individual's experience of well-being in all its forms and varieties are self-esteem and self-acceptance in particular. Without positive self-esteem, any achievements will be devalued and the level of well-being will be decreased accordingly. Studies have revealed that self-evaluation determines emotional reactions to social positive and negative evaluations. People with low self-esteem tend to evaluate comparisons with other people as having negative consequences, whereas individuals with high self-esteem are significantly less likely to show negative emotions in response to negative comparisons (Buunk et al., 1990).

The attitude towards oneself and one's past depends on social approval and condemnation. To empirically verify this regularity, regression analysis was used, in which the dependent variable was self-acceptance, whereas the independent - the evaluative reactions of others. The only factor of maintaining positive self-perception was social comparison. It explained $13.8 \%$ of the variance of self-acceptance and had the negative form: the more frequent 
Journal of Education Culture and Society No. 2_2021

social comparisons made by others, the lower the level of self-acceptance of the respondent is $(\beta=-0.371, p \leq .001)$.

The main results of the regression analysis are shown in Figure 1. The suitability of the statistical model was determined by the following criteria: $\mathrm{CMIN}=14.39, \mathrm{p}=.347 \geq .01 ; \mathrm{x}^{2} / \mathrm{df}=1.107 \leq 2 ; \mathrm{RMSEA}=.034 \leq .05$; LO90 = .000 $\leq .1 ;$ HI90 = .094 $\leq .1 ;$ PCLOSE $=.592 \geq .5 ;$ GFI $=.962 \geq .9$, $\mathrm{CFI}=.994 \geq .95, \mathrm{R}^{2}=.622$. Since the set of statistical criteria for the analysis of empirical data was diverse, $z$-scaling was used.

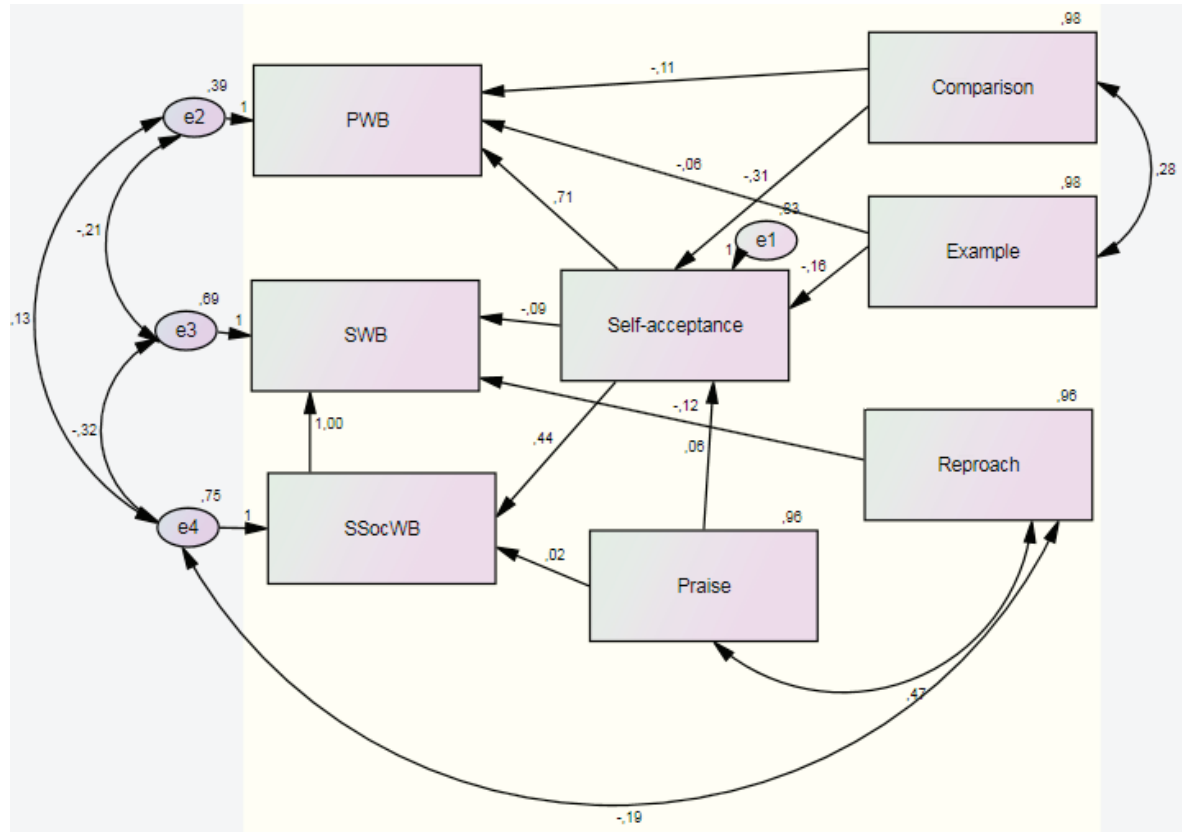

Fig. 1. Empirical model of the relationship between social evaluation and individual well-being

Source: own research.

\section{CONCLUSION}

The study found that the respondents' general level of individual well-being, as well as hedonistic well-being, eudemonic well-being and social well-being, is above average. The most important sources of evaluation in Ukrainian society are parents and a spouse; friends and colleagues play a relatively smaller role. There is no difference between men and women in terms of both well-being and the frequency of evaluation by others, as well as the nature of evaluation reactions.

The study also revealed the following trends: firstly, positive and neutral evaluations dominated in the key reference groups. Negative evaluations were 
more frequent from colleagues and friends, while positive evaluations - from family. Secondly, there were statistically significant differences between the groups with dominant positive and negative evaluation reactions from the reference groups in terms of subjective well-being, social acceptance (as a measure of social well-being) and competence. Thirdly, the key factors influencing an individual's experience were: a) reproaches from specific person led to a decrease in subjective well-being; b) reproaches from the members of reference groups reduce subjective social well-being, while praises increase it; c) frequent comparing with other people and having a role model reduce psychological well-being. However, the filter for the perception of positive and negative evaluations from the social environment is self-acceptance.

We see the prospects for further research concerning the influence of evaluative judgments in the systems of indirect communication (social networks) on an individual's experience of well-being.

\section{CONFLICT OF INTEREST DECLARATION}

The author declares that there are no potential conflicts of interest regarding the research, authorship and/or publication of this article.

\section{REFERENCES}

[1] Bernet, D. (2018). Счастливый мозг. Как работает мозг и откуда берется счастье [Нарру brain. How the brain works and where does happiness come from]. Moscow: Eksmo.

[2] Bers, S. A., \& Rodin, J. (1984). Social comparison jealousy: a developmental and motivational study. Journal of Personality and Social Psychology, 47(4), 766-779.

[3] Buchanan, K. E., \& Bardi, A. (2010). Acts of kindness and acts of novelty affect life satisfaction. The Journal of Social Psychology, 150(3), 235-237.

[4] Buunk, B. P., Collins, R. L., Taylor, S. E., VanYperen, N. W., \& Dakof, G. A. (1990). The affective consequences of social comparison: either direction has its ups and downs. Journal of Personality and Social Psychology, 59(6), 1238-1249.

[5] Danylchenko, T. V. (2014). Соціальне порівняння як фактор суб'єктивного благополуччя [Social comparison as a factor of subjective well-being]. Visnyk Chernihivskoho natsionalnoho pedahohichnoho universytetu imeni T.H. Shevchenka, 121(1), 103-109.

[6] Danylchenko, T. (2020). Correlation between level of personal well-being and spirituality. Journal of Education Culture and Society, 2, 267-280.

[7] Deci, E. L., \& Ryan, R. M. (2000). The "what" and "why" of goal pursuits: Human needs and the self-determination of behaviour. Psychological Inquiry, 11, 227-268.

[8] Dunning, D., \& Kruger, J. (1999). Unskilled and unaware of it: How difficulties in recognizing one's own incompetence lead to inflated self-assessments. Journal of Personality and Social Psychology, 77(6), 1121-1134.

[9] Izuma, K., Saito, D. N., \& Sadato, N. (2010). Processing of the incentive for social approval in the ventral striatum during charitable donation. Journal of Cognitive Neuroscience, 22(4), 621-631.

[10] Kahneman, D., \& Tversky, A. (1996). On the reality of cognitive illusions. Psychological Review, 103, 582-591.

[11] Libina, A. V. (2008). Совладающий интеллект: человек в сложной жизненной ситуации [Coping intelligence: A person in a difficult life situation]. Moscow: Eksmo.

[12] Mellor, K., \& Schiff, E. (1975). Discounting. Transactional Analysis Journal, 5(3), 295-302. https:// doi.org/10.1177/036215377500500321 
[13] Peralta, C. F., \& Saldanha, M. F. (2017). Can dealing with emotional exhaustion lead to enhanced happiness? The roles of planning and social support. Work $\mathcal{E}$ Stress, 31(2), 121-144. https:// doi.org/10.1080/02678373.2017.1308445

[14] Pronin, E., Lin, D. Y., \& Ross, L. (2002). The bias blind spot: Perceptions of bias in self versus others. Personality and Social Psychology Bulletin, 28, 369-381.

[15] Rodriguez, T. (2013). Negative emotions are key to well-being. Mind: Scientific American, 24(2), 26-27.

[16] Salovey, P., \& Rodin, J. (1984). Some antecedents and consequences of social-comparison jealousy. Journal of Personality and Social Psychology, 47(4), 780-792.

[17] Samoilenko, E. S. (2010). Эмоциональное отношение к социальному сравнению [Еmоtional attitude towards social comparison]. Eksperimental'naya psihologiya, 4, 87-103.

[18] Tesser, A. (1999). Toward a self-evaluation maintenance model of social behaviour. In R. F. Baumeister (Ed.), The self in social psychology (pp. 446-460). New York: Psychology Press

[19] Tesser, A., \& Collins, J. E. (1988). Emotion in social reflection and comparison situations: Intuitive, systematic, and exploratory approaches. Journal of Personality and Social Psychology, 55(5), 695-709.

[20] Tikhomirov, A. (2016). Самозащита [Self-defense]. Moscow: Izdatel'skie resheniya.

[21] Wilson, A. E., \& Ross, M. (2001). From chump to champ: People's appraisals of their earlier and present selves. Journal of Personality and Social Psychology, 80, 572-584.

[22] Zotova, O. Y. (2017). Психологическое благополучие личности [Psychological well-being of the personality]. Ekaterinburg: Gumanitarnyj universitet. 